\title{
AUDITOR INTERNAL UNIVERSITAS : SEBUAH PERGESERAN PARADIGMA DALAM MEWUJUDKAN GOOD UNIVERSITY GOVERNANCE
}

\author{
${ }^{1}$ Maria Yessica Halik, ${ }^{2}$ Carolus Askikarno Palalangan \\ Program Studi Akuntansi, Fakultas Ekonomi dan Bisnis, \\ Universitas Kristen Indonesia Paulus \\ marjesshalik@gmail.com
}

\begin{abstract}
ABSTRAK
Auditor internal adalah salah satu profesi pendukung yang mempromosikan praktik Good University Governance, yang saat ini berkembang menjadi hal utama untuk mencapai peningkatan efektivitas dan efisiensi di universitas. Penelitian ini bertujuan untuk mengetahui paradigma UKI Paulus tentang pentingnya fungsi auditor internal dalam mencapai Good University Governance. Rektor, tim penjaminan kualitas, dan wakil rektor keuangan UKI Paulus adalah responden dari penelitian ini. Dengan menggunakan desain penelitian kualitatif dengan pendekatan deskriptif, hasil penelitian ini adalah paradigma UKI Paulus tentang audit internal universitas belum begitu penting karena UKI Paulus belum membentuk divisi khusus audit internal dalam kampus yang bersifat independen. Proses pemeriksaan keuangan UKI Paulus masih dilaksanakan pihak yayasan. Hal ini disebabkan karena beberapa faktor seperti belum adanya standar dan aturan khusus tentang audit internal.

Kata Kunci: audit internal, Good University Governance (GUG)
\end{abstract}

\section{ABSTRACT}

Internal auditor is one of the supporting profession that promote the practice of Good University Governance, which nowadays is evolving to become a primary thing to achieve the enhancement of effectivity and efficiency in university. This study aims to find out the UKI Paulus' paradigm about the importance of internal auditor function in achieve Good University Governance. Chancellor, quality assurance team, and vice chancellor of finance of UKI Paulus are the respondents of this study. By using a qualitative research design with a descriptive approach, the results of this study are that the UKI Paulus paradigm regarding university internal audit has not been so important because UKI Paulus has not yet formed a special division of internal audit within an independent campus. The UKI Paulus financial audit process is still being carried out by the foundation. This is due to several factors such as the absence of specific standards and rules regarding internal audit.

Keywords: internal auditor, Good University Governance (GUG)

\section{PENDAHULUAN}

Keberhasilan dalam penyajian dan penyerapan ilmu karena ditunjang dengan kualitas pendidik, layanan administrasi, sarana dan prasarana serta infrastruktur pendukung lainnya menjadi faktor yang sangat menentukan. Tentunya perguruan 


\section{Buana Akuntansi}

tinggi yang berkualitaslah yang akan menjadi pilihan pertama bagi calon mahasiswa untuk menempuh pendidikan. Tolak ukur kualitas perguruan tinggi tersebut dapat dilihat dari sarjana-sarjana yang dicetak apakah mampu bersaing di dunia kerja atau malah hanya menjadi pengangguran terdidik.

Menurut laporan Organization for Economic Cooperation and Development, perusahaan-perusahaan di Indonesia sangat sulit mendapatkan lulusan yang siap pakai dan dapat berpikir kritis. Lebih jauh lagi, survei yang dilakukan oleh World Bank menemukan sekitar 20 - 25 persen lulusan perguruan tinggi lokal memerlukan pelatihan ulang sebelum dapat bekerja. Demikian pula universitas- universitas dari Indonesia masih tertinggal dari negara-negara sekitarnya. Dari sisi global competitiveness, sangat kontras jika dibandingkan dengan India misalnya, di mana lulusan sarjana, master, sampai doktor dari India sangat diminati dan banyak terpakai di berbagai negara, termasuk juga sudah membanjiri Indonesia (Koran Jakarta, 2012).

Begitu pentingnya mutu bagi pendidikan, pemerintah menerbitkan Peraturan Pemerintah (PP) No 19 Tahun 2005 mengenai Standar Pendidikan Nasional, yang pada pasal 91 menyatakan Setiap Satuan pendidikan pada jalur Formal dan non formal wajib melakukan penjaminan mutu pendidikan. Undang- Undang No. 20 Tahun 2003 tentang Sistem Pendidikan Nasional dan Peraturan Pemerintah No. 19 Tahun 2005 tentang Standar Nasional Pendidikan menegaskan bahwa penjaminan mutu merupakan hal yang wajib dalam sebuah Perguruan Tinggi dan setiap Perguruan Tinggi diberi kebebasan untuk menentukan sendiri standar mutunya serta mekanisme pemenuhan standar tersebut. Sejak ditetapkannya Peraturan Pemerintah No. 19 tahun 2005, Sistem Penjaminan Mutu Perguruan Tinggi tidak lagi hanya terfokus pada bidang akademik, tetapi juga meliputi bidang non akademik.

Perguruan Tinggi yang mampu mengelola sumber daya secara tepat akan mampu memenuhi tuntutan kualitas pendidikan. Berbagai upaya terus dilakukan demi tercapainya visi dan misi Perguruan Tinggi. Untuk itu perlu diadakan pengawasan dan pemeriksaan pada setiap langkah kegiatan dalam manajemen yaitu mulai dari tahap perencanaan, pengorganisasian, kepemimpinan sampai dengan 


\section{Buana Akuntansi}

pengendalian. Selain pada tahap-tahap dalam manajemen, pengawasan dan pemeriksaan juga diperlukan pada semua kebijakan dan prosedur yang dilaksanakan oleh setiap unit-unit dari Perguruan Tinggi. Dengan demikian diperlukan adanya sebuah tim atau sekelompok staf dari berbagai unit yang bertugas untuk melakukan audit internal yaitu memeriksa, mengawasi dan memberikan saran perbaikan bila diperlukan.

Audit Internal merupakan suatu fungsi penilaian independen dalam sebuah organisasi yang bertujuan untuk menguji dan mengevaluasi dari semua kegiatankegiatan yang dilakukan organisasi tersebut, sehingga manajemen puncak dapat memiliki sumber informasi dari setiap unit yang dimilikinya. Untuk itu pemeriksa internal atau audit internal akan melakukan analisis, penilaian dan memberi rekomendasi serta saran-saran (Tugiman, 1997: 5). Audit Internal yang dilaksanakan oleh seorang auditor internal yang berkompeten akan meningkatkan nilai tambah suatu organisasi. Beberapa perguruan tinggi baik negeri maupun swasta di Indonesia sudah membentuk internal audit dalam memeriksa, mengawasi dan memberikan sara

Dalam menghadapi tantangan perubahan, auditor internal wajib menyesuaikan diri dan meninggalkan paradigma lama yang berfokus pada kegiatan pengendalian yang disertai dengan pendekatan kepatuhan kepada regulasi dan undang-undang serta prosedur intern. Paradigma lama serupa dengan peran polisi atau watchdog yang mempunyai tugas memeriksa, yang sering kali dilihat oleh manajemen sebagai tindakan konfrontatif (Tampubolon, 2005: 65). Perubahan paradigma audit internal akan efektif apabila pimpinan organisasi memahami dengan baik peran auditor internal. Tidak sedikit manajemen organisasi masih bingung terhadap peran auditor internal yang seharusnya, bahkan ada auditor internal organisasi yang tidak berfungsi (Tugiman, 2007: 11). Seiring dengan kebutuhan organisasi yang semakin berkembang maka peran auditor internal bertambah menjadi konsultan, yang mempunyai tugas untuk memberi masukan berbagai masalah yang berhubungan dengan sumber daya yang dimiliki dalam organisasi tersebut dan catalyst yang ikut berperan serta menentukan tujuan dari 


\section{Buana Akuntansi}

organisasi yang ikut dalam memastikan bahwa kontrol intern telah berfungsi dengan baik (Tampubolon, 2005: 65).

Pada kenyataannya, pembentukan internal audit pada perguruan tinggi tidak didasarkan pada kebutuhan akan peran internal audit, namun lebih pada pelengkap administratif struktur organisasi (Aisyah dkk, 2013). Banyak tim internal audit di berbagai perguruan tinggi, tidak dapat berfungsi dengan baik karena internal audit dibentuk di masing-masing perguruan tinggi secara tidak memadai dari sisi jumlah sumber daya manusia yang dialokasikan, kualifikasi yang harus dipenuhi oleh tim internal audit, maupun pendanaan program kegiatan dan aktivitas internal audit. Secara empiris, belum ada hasil penelitian yang dapat menunjukkan bahwa para pemimpin perguruan tinggi di Indonesia benar-benar memiliki persepsi dan anggapan yang sama mengenai peran internal audit.

Publikasi penelitian mengenai peran audit internal di perguruan tinggi Indonesia belum banyak. Hasil kegiatan monitoring dan evaluasi oleh Inspektorat Jenderal mengenai keberadaan audit internal dijadikan informasi untuk kepentingan internal saja. Penelitian yang dilakukan oleh Yuniarti dan Apandi (2012) mengenai gejala fraud dan peran auditor internal dalam pendeteksian fraud di lingkungan perguruan tinggi menunjukkan bahwa fraud terjadi karena lemahnya pengendalian internal dan anomali akuntansi. Auditor internal tak dapat berbuat banyak tanpa dukungan top management universitas. Penelitian ini memiliki banyak kelemahan. Pertama, latar belakang dan karakteristik auditor internal yang berada di perguruan tinggi tidak dianalisis secara dalam apakah auditor internal yang dibentuk diperguruan tinggi telah memiliki kemampuan dan keahlian dalam menguasai teknik pendeteksian fraud. Kedua, responden yang digunakan dalam penelitian sangat terbatas (lima orang).

Sari dan Raharja (2012) melakukan penelitian mengenai pengaruh peran auditor internal terhadap mekanisme Good Corporate Governance (GCG) pada Badan Layanan Umum. Hasilnya menunjukkan adanya pengaruh yang signifikan atas peran auditor internal terhadap mekanisme GCG. 


\section{Buana Akuntansi}

Dalam upaya mewujudkan Good Governance dalam hal ini Good University Governance (GUG), Universitas Kristen Indonesia Paulus memerlukan peran audit internal yang bertugas meneliti mengevaluasi suatu sistem akuntansi serta menilai kebijakan manajemen yang dilaksanakan. Auditor internal merupakan salah satu profesi yang menunjang terwujudnya GUG yang pada saat ini telah berkembang menjadi komponen utama dalam meningkatkan universitas secara efektif dan efisien.

Berdasarkan latar belakang tersebut, penulis mengangkat judul penelitian "Auditor Internal Universitas : Sebuah Pergeseran Paradigma dalam Mewujudkan Good University Governance".

\section{METODE PENELITIAN}

\section{Pendekatan Penelitian}

Penelitian ini merupakan penelitian kualitatif dengan pendekatan deskriptif. Menurut Sugiyono (2012), metode penelitian kualitatif merupakan metode penelitian yang dilandasi oleh filsafat postivisme, yang kegunaannya untuk meneliti kondisi objek alamiah. Pengambilan sampel sumber data dapat dilakukan secara purposive ataupun snowball, yang hasilnya akan lebih menekankan makna dari pada generalisasi. Selain itu, pendekatan deskriptif digunakan untuk mengumpulkan informasi sebanyak-banyaknya melalui berbagai teknik. Metode deskriptif analitis merupakan metode yang bertujuan untuk mendeskripsikan atau memberi gambaran tentang objek penelitian melalui sampel atau data yang terkumpul dan membuat kesimpulan secara umum (Sugiyono, 2012).

Dalam penelitian ini, peneliti berniat untuk menjelaskan atau mendeskripsikan fenomena-fenomena yang berkaitan dengan proses audit internal yang dilaksanakan di Universitas Kristen Indonesia Paulus (UKI Paulus) Makassar. Penelitian ini tidak bertujuan untuk memberikan penilaian dan pemecahan masalah terkait pelaksanaan audit internal di UKI Paulus.

Teknik Pemilihan Informan 


\section{Buana Akuntansi}

Pemilihan subjek penelitian menggunakan teknik nonprobability sampling, yaitu tidak semua elemen populasi memiliki kesempatan untuk dijadikan sampel (Sekaran dan Bougie 2013). Elemen atau pihak yang dipilih untuk dijadikan informan ialah pihak-phak yang dianggap memiliki pemahaman yang baik terkait dengan pelaksanaan audit internal di UKI Paulus, misalnya tim audit internal (auditor dan timnya), rektor, badan penjaminan mutu, atau pihak lain yang memahami dan berkaitan dengan pelaksanaan audit internal.

\section{Sumber Data}

\section{Data primer}

Data primer ialah data yang diperoleh secara langsung dari subjek atau partisipan penelitian melalui wawancara (interview) secara mendalam untuk memperoleh opini partisipan terkait masalah penelitian. Data primer dalam penelitian ini ialah data berupa hasil wawancara dengan beberapa orang partisipan yang memahami pelaksanaan audit internal.

\section{Data sekunder}

Menurut Sugiyono (2012), data sekunder merupakan data yang didapatkan secara tidak langsung dari subjek atau partisipan penelitian, melainkan dari sarana lain, misalnya berupa dokumen. Data sekunder yang digunakan dalam penelitian ini, ialah arsip dan dokumen yang berhubungan dengan masalah penelitian, misalnya dokumen laporan audit; dokumen pedoman audit/audit mutu internal; dokumen standar audit; dokumen standar operasional prosedur (SOP); dan dokumen lainnya.

\section{Teknik Pengumpulan Data}

Data penelitian dikumpulkan dengan menggunakan beberapa teknik, antara lain:

1) Wawancara (interview), yaitu wawancara semi-terstruktur, yang pelaksanaannya lebih bebas dan tidak kaku seperti wawancara terstruktur. Wawancara semi-terstruktur dilakukan dengan lebih terbuka, yaitu pihak yang diwawancarai dimintai pendapat. Ide-idenya tidak ada alternatif jawaban yang disediakan oleh peneliti (Sugiyono, 2012). Peneliti akan 


\section{Buana Akuntansi}

mewawancarai partisipan atau informan yang telah ditetapkan berdasarkan hubungan mereka dalam proses audit internal. Yang akan diwawancarai antara lain: pimpinan universitas, pengurus yayasan, dan badan penjaminan mutu universitas.

2) Analisis Dokumen, yaitu menganalisis dan mempelajari dokumen dan informasi yang relevan terhadap masalah penelitian. Dokumen yang digunakan dalam penelitian ini, ialah dokumen yang berhubungan dengan masalah penelitian, misalnya dokumen laporan audit; dokumen pedoman audit/audit mutu internal; dokumen standar audit; dokumen standar operasional prosedur (SOP); dan dokumen lainnya.

\section{Teknik Analisis Data}

Terdapat tiga langkah analisis data kualitatif menurut Miles and Huberman (1994) dalam Sekaran dan Bougie (2013), antara lain sebagai berikut:

1) Reduksi Data

Reduksi data digunakan untuk merangkum data kualitatif yang terkadang terlalu banyak. Data yang pokok atau penting diambil dan diklasifikasikan dengan menggunakan kode tertentu. Sedangkan data yang dianggap tidak penting dan tidak berkaitan dengan fenomena masalah penelitian dihapus.

2) Penyajian Data

Penyajian data, yaitu bagaimana data disajikan dalam bentuk kalimat, grafik, atau diagram sehingga dapat dipahami oleh peneliti dan pembaca (Sekaran dan Bougie 2013). Karena penelitian ini merupakan penelitian kualitatif yang berfokus pada masalah yang terjadi pada objek penelitian, peneliti lebih banyak menggunakan kata-kata dalam bentuk kalimat untuk menceritakan permasalahan secara detail. Tabel digunakan untuk menyajikan kesimpulan temuan sehingga lebih mudah dibaca dan dipahami.

3) Konklusi dan Verifikasi 


\section{Buana Akuntansi}

Berdasarkan Sekaran dan Bougie (2013), tahap terakhir dari suatu penelitian ialah tahap penarikan kesimpulan awal, dan verifikasi untuk meyakinkan bahwa temuan telah valid dan didukung oleh bukti yang kuat.

\section{HASIL DAN PEMBAHASAN}

\section{Fungsi Audit Internal di UKI Paulus}

UKI Paulus merupakan salah satu perguruan tinggi swasta (PTS) terbaik di wilayah Timur Indonesia, yang berdiri sejak kurang lebih 65 tahun yang lalu, yang memiliki 4 Fakultas dan 10 program studi. UKI Paulus berada di bawah kepemilikan Yayasan Pendidikan Intelegensia Kristen Indonesia (PIKI) Paulus. Fungsi audit internal pada UKI Paulus dilaksanakan untuk memperoleh keyakinan memadai atas laporan keuangan dan pertanggungjawaban kegiatan operasional universitas. Saat ini, belum ada divisi khusus audit internal yang dibentuk untuk melaksanakan fungsi audit internal, melainkan fungsi ini masih dijalankan oleh pihak Yayasan.

Belum adanya divisi khusus audit internal menyebabkan belum sempurnanya proses pelaksanaan audit internal, khususnya mulai dari tahapan rekrutmen anggota, penyusunan buku manual audit, sampai pada proses penyusunan laporan hasil audit. Fungsi audit internal yang dilaksanakan oleh yayasan terbatas pada evaluasi aktivitas, baik keuangan maupun operasional universitas. Padahal, berdasarkan IIA menyatakan bahwa:

"internal auditing is an independent, objective assurance, and consulting activity designed to add value and improve and organization's operations. It helps an organization accomplish its objectives by bringing a systematic, disciplined approach to evaluate and improve the effectiveness of risk management, control, and governance processes."

Pengertian di atas memberikan penjelasan bahwa audit internal yang dilaksanakan oleh yayasan terbatas pada fungsi evaluasi, sedangkan fungsi konsultasi dan asurans belum terlihat pelaksanaannya. Dengan demikian, dapat diketahui bahwa fungsi evaluasi dalam audit internal di UKI Paulus sudah dilaksanakan, namun 


\section{Buana Akuntansi}

belum ada divisi khusus yang bertindak sebagai divisi audit internal (divisi ini belum dibentuk).

\section{Praktik Audit Internal yang Dilaksanakan di UKI Paulus}

Fungsi audit internal yang dijalankan oleh yayasan telah berlangsung selama 2 tahun terakhir, yaitu sejak tahun 2017. Audit dilaksanakan dua kali dalam setahun atau setiap akhir semester. Selama empat kali audit internal dilakukan, terdapat beberapa hal yang patut menjadi perhatian universitas secara internal. Hal-hal tersebut antara lain sebagai berikut.

a) Belum terbentuknya komite audit internal, yang secara independent bertindak melaksanakan fungsi audit internal, yaitu memberikan jasa asurans, konsultasi, dan mengevaluasi kegiatan operasional dan keuangan universitas. Evaluasi ini selanjutnya bertujuan untuk menilai kelebihan dan kekurangan, serta ancaman dan peluang, yang dimiliki dan dihadapi oleh universitas. Pada akhirnya, audit internal bertujuan untuk membantu universitas dalam mempersiapkan diri menghadapi audit eksternal maupun akreditasi.

b) Orang-orang yang ditugaskan sebagai auditor internal ialah anggota yayasan yang ditunjuk langsung oleh pihak yayasan sendiri, yang berbeda-beda setiap tahunnya. Hal ini dapat menyebabkan proses audit internal yang kurang maksimal karena setiap tahun auditor internal berganti, sehingga pengenalan dan pemahaman akan kondisi audit kurang memadai.

c) Selain belum terbentuknya komite audit internal, aturan atau buku pedoman pelaksanaan audit internal juga belum disusun. Hal ini mengakibatkan tidak adanya standar yang jelas tentang proses audit internal yang dilakukan oleh tim auditor (dari pihak yayasan), maupun standar pelaporan audit.

d) Dalam melaksanakan tugas evaluasi, tim auditor dari pihak yayasan tidak membuat standar perencanaan kinerja, bahwa penanggung jawab fungsi audit internal seharusnya membuat perencanaan berbasis risiko, yang konsisten dengan tujuan organisasi. Perencanaan yang tidak mantap dapat 
menyebabkan tidak efektifnya fungsi audit internal, hanya sebatas kegiatan evaluasi dan pemeriksaan laporan keuangan universitas saja.

e) Pihak yayasan yang bertugas menjalankan fungsi audit internal terbatas pada fungsi pengawasan dan evaluasi saja, tidak menjalankan fungsi konsultasi. Ini berarti bahwa fungsi audit internal semata-mata hanya dijalankan untuk melihat kepatuhan universitas dalam mempertanggungjawabkan keuangan dan kegiatan operasionalnya kepada pihak yayasan. Tidak dilaksanakannya fungsi konsultasi dan jasa asurans menyebabkan ketidaksiapan universitas apabila nantinya akan diperiksa/diaudit secara eksternal.

\section{Faktor-faktor yang Mempengaruhi Aktivitas Fungsi Audit Internal UKI Paulus}

\section{1) Anggota/Staff Audit Internal}

Belum terbentuknya komite audit internal menyebabkan belum adanya anggota/staff yang bertindak khusus sebagai auditor internal. Sejauh ini yang bertindak sebagai anggota audit internal hanyalah anggota yayasan yang ditunjuk oleh pimpinan yayasan untuk melakukan pemeriksaan laporan keuangan universitas. Dari hasil wawancara yang dilakukan terhadap pimpinan universitas, khususnya pada bagian keuangan, dapat diketahui bahwa jumlah anggota/staff audit yang turut serta dalam proses audit internal sangat mempengaruhi aktivitas fungsi audit internal. Sampai saat penelitian ini selesai dilaksanakan, jumlah anggota/staff audit internal dirasakan masih kurang, baik dari segi kuantitas, maupun kualitas. Kutipan wawancaranya sebagai berikut:

"auditor internal yang memeriksa kami selama ini dari pihak yayasan. Dari segi kemampuan sebenarnya tidak kurang juga sih, karena mereka-mereka ini adalah orang yang sudah berpengalaman dalam penyusunan laporan keuangan universitas, tapi setahu saya mereka tidak punya sertifikat auditor atau akuntan internal sih. Jumlahnya juga belum cukup menurut saya."

\section{2) Dukungan dari Top Management}

Dukungan manajemen puncak sangat mempengaruhi jalannya fungsi audit internal. Berdasarkan hasil wawancara dapat diketahui bahwa manajemen 
puncak memberikan dukungan berupa akses bagi auditor internal dalam melaksanakan proses audit. Seperti pada kutipan wawancara sebagai berikut:

"kami mendukung setiap proses audit yang dilaksanakan oleh auditor internal. Ya, namanya juga dari yayasan, tentu saja kami harus patuh dan menyediakan segala dokumen dan akses yang dibutuhkan oleh mereka."

\section{3) Pelatihan}

Pelatihan merupakan salah satu cara atau sarana untuk meningkatkan kemampuan auditor dalam melaksanakan fungsi audit internal pada universitas. Berdasarkan Ahmad et al. (2009), diketahui bahwa kurangnya pelatihan dapat mengakibatkan rendahnya tingkat efektivitas fungsi audit internal. Selama ini pelatihan audit internal justru diikuti oleh Badan Penjaminan Mutu (BPM) UKI Paulus, sedangkan anggota/staff yang bertindak sebagai auditor internal dari yayasan justru sangat jarang mengikuti pelatihan terkait. Kutipan wawancara dengan pihak yayasan terkait hal tersebut, yaitu:

"saya sih pernah ikuti pelatihan sejenis itu, pelatihan audit internal, tapi sudah lama sekali. Yang saya tahu, itu pun karena saya lihat mata anggaran di setiap unit yang mengajukan kebutuhan dana, unit BPM yang pernah ikuti pelatihan semacam itu. Saya masih ingat sedikit-sedikit cara mengaudit, ya intinya kita dari pihak yayasan wajib mencocokkan anggaran yang dikeluarkan dengan bukti-bukti pengeluarannya."

Kutipan wawancara di atas menerangkan bahwa staff audit internal dari yayasan belum pernah mengikuti pelatihan audit terkini. Hal ini mengindikasikan kurang maksimalnya kemampuan audit yang dimiliki oleh pihak auditor internal UKI Paulus, yang mungkin juga menjadi penyebab belum dapat dilaksanakannya fungsi audit internal secara lengkap, hanya mampu mengevaluasi pelaporan keuangan dan penggunaan anggaran saja.

\section{4) Tingkat Independensi}


Independen tidaknya fungsi audit internal dapat dinilai dari posisi fungsi tersebut dalam universitas. Berdasarkan informasi yang dipaparkan sebelumnya, dapat diketahui bahwa fungsi audit internal dilaksanakan oleh pihak yayasan, yang membawahi universitas, yaitu universitas bertanggung jawab kepada yayasan. Oleh karena itu, dapat disimpulkan bahwa tingkat independensi fungsi audit internal di UKI Paulus sudah cukup baik karena dilaksanakan oleh pihak yang semestinya.

\section{5) Kompetensi Auditor}

Seperti kutipan wawancara pada nomor 1) dan 3) di atas, dapat diketahui bahwa pihak yang bertindak sebagai auditor internal merupakan orang-orang yang memiliki pengalaman yang mumpuni dalam pelaporan keuangan universitas. Namun, para auditor ini sebagian besar tidak memiliki sertifikat auditor internal, bahkan ada yang tidak berlatar belakang ilmu akuntansi. Kurangnya kompetensi auditor ini pula yang dapat menjadi penyebab tidak sempurnanya fungsi audit internal yang selama ini dijalankan di UKI Paulus.

\section{6) Tindak Lanjut Hasil Audit}

Setelah melakukan serangkaian prosedur audit, auditor internal melaporkan hasil audit dalam suati dokumen yang berisi temuan dari kasus-kasus yang muncul. Laporan ini selanjutnya diserahkan kepada pimpinan universitas dan dibahas bersama dalam rapat pimpinan, untuk selanjutnya ditindaklanjuti. Setiap temuan yang dilaporkan dalam laporan hasil audit tersebut akan ditindaklanjuti oleh pimpinan universitas, sehingga tidak terjadi lagi kesalahan yang dilakukan oleh auditee pada proses audit berikutnya.

\section{SIMPULAN}

\section{Simpulan}

Berdasarkan hasil penelitian, dapat disimpulan bahwa paradigma UKI Paulus tentang audit internal universitas belum begitu penting karena UKI Paulus belum membentuk divisi khusus audit internal dalam kampus yang bersifat independen. 


\section{Buana Akuntansi}

Proses pemeriksaan keuangan UKI Paulus masih dilaksanakan pihak yayasan. Hal ini disebabkan karena beberapa faktor seperti belum adanya standar dan aturan khusus tentang audit internal. Dalam proses audit yang dilaksanakan oleh pihak yayasan, ada beberapa terdapat beberapa faktor yang menyebabkan proses audit belum berjalan secara efektif dan efisien. Faktor-faktor tersebut secara langsung maupun tidak langsung telah mempengaruhi aktivitas yayasan dalam melakukan proses audit. Dari beberapa faktor yang sudah diungkapkan, beberapa faktor yang ternyata mendukung aktivitas divisi audit internal di UKI Paulus adalah dukungan / komitmen dari manajemen puncak, independensi, tindaklanjut dari temuan dan rekomendasi oleh auditee / manajemen, serta pengalaman dari staff pada fungsi audit internal. Sedangkan beberapa faktor yang tidak mendukung aktivitas divisi audit internal di UKI Paulus adalah jumlah staff audit internal, pelatihan, serta kompetensi / pengetahuan staff dalam teknik-teknik audit. Dalam hubungan dengan Good Corporate Governance (GCG), UKI Paulus belum optimal dalam menerapkan Good Corporate Governance, karena mekanisme auditor internal dalam mengevalusi proses sistem keuangan universitas belum memadai.

\section{Implikasi}

Implikasi penelitian ini adalah penetapan posisi yang strategis bagi divisi audit internal, yang dapat menunjang independensi dan dapat memperkuat fungsi pengawasan fungsi audit internal. Kedua, disahkannya standar dan aturan yang jelas tentang audit internal di UKI Paulus. Ketiga, kebijakan yang jelas dari pimpinan universitas mengenai tugas dan kewenangan Divisi Audit Internal. Keempat, dibuatnya rencana pelatihan bagi auditor internal dan ditingkatkannya jumlah pelatihan bagi unit. Kelima, posisi kepala auditor internal yang tidak dirubah-rubah/rangkap jabatan dengan posisi lain dalam organisasi.

\section{DAFTAR PUSTAKA}

Dirjen Dikti. 2018. “Pengertian Audit Mutu Internal”. Diakses pada 27 Juni 2019. https://www.atmajaya.ac.id/filecontent/lpm-MATERI-01-PENGERTIAN-AUDITMUTU-INTERNAL.pdf 


\section{Buana Akuntansi}

Harris, J., dan G. Cunningham. (2009). “The Time are Changing: A Call for Governing Boards of Universities to Awaken to Sarbanes-Oxley and Practices of Good Governance". Decision Line, 40 (5), 21.

Institute of Internal Auditors. 2017. Global Perspectives: Audit Internal dan Audit Eksternal. IIA Global.

Muktiyanto, Ali. 2016. "Good University Governance dan Kinerja Perguruan Tinggi". Institusi Pendidikan Tinggi di Era Digital: Pemikiran, Permodelan dan Praktek Baik.

Mulyadi. 2010. Auditing Edisi Keenam Buku 1. Jakarta: Salemba Empat.

Naheem, Mohammed Ahmad. 2016. "Internal Audit Function and AML Compliance: The Globalization of the Internal Audit Function". Journal of Money Laundering Control, 19 (4), 459-469.

Quyen, Do Thi Ngoc. 2014. “Developing University Governance Indicators and Their Weighting System using a Modified Delphi Method". Procedia-Socia and Behavioral Sciences 141, 828-833.

Reid, Kein dan David Ashelby. 2002. “The Swansea Internal Quality Audit Processes: A Case Study". Quality Assurance in Education 10, No. 4: 237-245.

Sekaran, Uma, dan Roger Bougie. 2013. Research Methods for Business: A Skill-Building Approach. United Kingdom: Wiley.

Soh, Dominic S.B., dan Nonna Martinov Bennie. 2011. “The Internal Audit Function: Perceptions of Internal Audit Roles, Effectiveness and Evaluation". Managerial Auditing Journal, 26 (7), 605-622.

Sugiyono. 2012. Metode Penelitian Kuantitatif, Kualitatif, dan RED. Bandung: Alfabeta. 